\title{
STUDI TENTANG PEMBUATAN DESAIN MOTIF BATIKLONTARA.COM
}

\author{
Maghfira Maulani Patappa \\ Pendidikan Seni Rupa, Fakultas Seni dan Desain, Universitas Negeri Makassar \\ maghfiramaulani.9@gmail.com
}

\begin{abstract}
Abstrak
Penelitian ini bertujuan untuk mengetahui proses pembuatan desain motif dan penerapan unsur dan prinsip desain dalam pembuatan desain motif Batiklontara.com. Penelitian ini adalah penelitian deskriptif kualitatif tentang pembuatan desain motif Batiklontara.com. Teknik pengumpulan data yang digunakan adalah observasi, wawancara, dan dokumentasi. Penelitian ini berfokus pada proses pembuatan desain Batiklontara.com dengan memperhatikan unsur dan prinsip desain dalam proses pembuatannya, dengan memperoleh informasi dari Rachmat Nurfansyah, pemilik Batiklontara.com, dan desainer Batiklontara.com, Mustakim dan Darmadi. Adapun data yang dihasilkan adalah proses pembuatan desain motif Batiklontara.com memiliki 2 proses, yaitu dengan metode manual dan metode desain grafis. Proses pembuatan dengan menggunakan metode manual diawali dengan proses pembuatan sketsa awal, kemudian sketsa di scan menjadi bentuk file gambar, lalu digambar kembali menggunakan pen tablet melalui software Adobe Illustrator CC. setelah file diubah ke dalam bentuk vektor, ekspor file gambar tersebut ke dalam software Coreldraw X8 untuk penyusunan komposisi gambar pada kain batik. Setelah itu, desain yang sudah dikomposisikan kemudian memasuki proses pewarnaan. Desain yang telah jadi kemudian diaplikasikan ke dalam bentuk mockup menggunakan software Adobe Photoshop CC. Adapun proses pembuatan menggunakan metode desain grafis memiliki perbedaan hanya di bagian pembuatan sketsa awal. Selebihnya cara dan prosesnya sama saja. Unsur desain yang diterapkan dalam proses pembuatan desain motif Batiklontara.com yaitu garis, contohnya seperti garis lengkung, garis lurus, garis diagonal, garis gradasi, garis putus-putus, garis diagonal, garis zigzag dan garis vertikal. bidang, dan warna. Sedangkan prinsip desain yang diterapkan dalam proses pembuatan desain yaitu prinsip keseimbangan, tekanan, irama, dan kesatuan.
\end{abstract}

Kata kunci: desain; motif; batiklontara

\begin{abstract}
This study aims to determine the process of making motif designs and the application of elements and design principles in making Batiklontara.com motif designs. This research is a qualitative descriptive study of the making of Batiklontara.com motif designs. Data collection techniques used are observation, interviews, and documentation. This research focuses on the process of making Batiklontara.com design by paying attention to the elements and design principles in the manufacturing process, by obtaining information from Rachmat Nurfansyah, owner of Batiklontara.com, and designers Batiklontara.com, Mustakim and Darmadi. The data generated in the process of making motif designs Batiklontara.com has 2 processes, namely by manual methods and graphic design methods. The manufacturing process using the manual method begins with the process of making the initial sketch, then the sketch is scanned into an image file form, then drawn back using the tablet pen through Adobe Illustrator CC software. after the file is converted into vector form, export the image file into the Coreldraw X8 software for composing the composition of the image on batik cloth. After that, the composited design then enters the coloring process. The finished design is then applied to a mockup using
\end{abstract}


Adobe Photoshop CC software. The manufacturing process using the graphic design method has a difference only in the making of the initial sketch. The rest of the methods and processes are the same. The design elements applied in the process of making Batiklontara.com motif designs are lines, for example, such as curved lines, straight lines, diagonal lines, gradation lines, dashed lines, diagonal lines, zigzag lines, and vertical lines. fields, and colors. While the design principles applied in the design process are the principles of balance, pressure, rhythm, and unity.

Keywords: design; motive; batiklontara

\section{PENDAHULUAN}

Batik merupakan salah satu contoh corak kebudayaan yang telah menjadi identitas bangsa Indonesia. Batik telah menjadi salah satu warisan bangsa yang sudah dikenal sejak zaman Kerajaan Majapahit dan masa penyebaran Islam. Istilah batik berasal dari bahasa Jawa, yaitu amba dan titik. Amba berarti kain, dan titik adalah cara memberi motif pada kain menggunakan bahan yang disebut malam cair dengan cara dititik-titik.

Batik pada awalnya hanya dikenakan oleh keluarga kerajaan beserta pengikutnya saja. Akan tetapi, seiring berjalannya waktu, batik pun mulai berkembang di masyarakat luas hingga saat ini. Tidak hanya di pulau Jawa, batik juga sudah berkembang pesat di daerahdaerah luar Jawa, contohnya di Sulawesi Selatan (Sulsel).

Sulsel dengan beberapa suku yang ada memiliki kekayaan kesenian yang beragam. Salah satu kesenian yang ada di Sulsel ialah kesenian batik. Di Sulsel, batik memiliki pasar tersendiri untuk seni, budaya dan usaha. Untuk kualitasnya, batik Sulsel pun tak kalah pesona dari batik yang diproduksi oleh provinsi lain di Indonesia. Hal tersebut dapat dilihat dari batik Sulsel yang memiliki motif dan corak yang unik.

Batik memiliki ciri identitas tersendiri. Anesia Aryunda Dofa (1996: 25) menjelaskan bahwa ciri identitas nasional batik terdapat kekhasan motif batik yang beraneka ragam dari yang rumit hingga motif yang paling indah. Di setiap daerah, batik memiliki kekhasan masing- masing yang dipengaruhi oleh alam, lingkungan, tradisi masyarakat, budaya daerah, keagamaan, dan lapisan strata sosial masyarakatnya. Begitu pun dengan batik yang dibuat oleh para pengrajin di Sulsel. Batik Sulsel memiiki berbagai motif. Salah satu motif yang umum digunakan batik Sulsel adalah motif aksara lontara.

Batik Sulsel umumnya mengangkat aksara lontara untuk dijadikan motif batik dengan ungkapan-ungkapan dan peribahasa yang menggambarkan nasihat atau petuah-petuah leluhur.Munculnya Batiklontara.com didasari oleh keinginan untuk melestarikan budaya aksara lontara dalam sebuah media baru, yakni melalui batik. Aksara lontara adalah aksara tradisional masyarakat Bugis dan Makassar. Dari uraian latar belakang di atas, dapat dilihat bahwa Batik Sulsel dengan motif aksara lontara mengalami perkembangan yang pesat. Oleh karena itu, penulis tertarik untuk mendalami perkembangan tersebut melalui penelitian dengan judul "Studi tentang Pembuatan Desain Motif Batiklontara.com".

Tujuan yang ingin dicapai dalam penelitian ini adalah (1) Mengetahui proses pembuatan desain motif Batiklontara.com (2) Mengetahui penerapan unsur dan prinsip desain dalam pembuatan desain motif Batiklontara.com

Hasil penelitian ini diharapkan dapat memberikan manfaat baik teoritis maupun praktis bagi guru, siswa, peneliti, dan semua yang terkait dengan dunia pendidikan, adapun manfaatnya adalah: (1) Teoritis, Menambah referensi tentang batik khususnya motif dalam perkembangan 
batik di Indonesia, dan menambah pengetahuan tentang motif batik khususnya motif Batiklontara.com. (2) Praktis: Memberikan informasi khususnya kepada mahasiswa Program Studi Pendidikan Seni Rupa, Fakultas Seni dan Desain Universitas Negeri Makassar terkait proses pembuatan desain motif Batik, serta penerapan unsur dan prinsip desain dalam pembuatan motif batik.

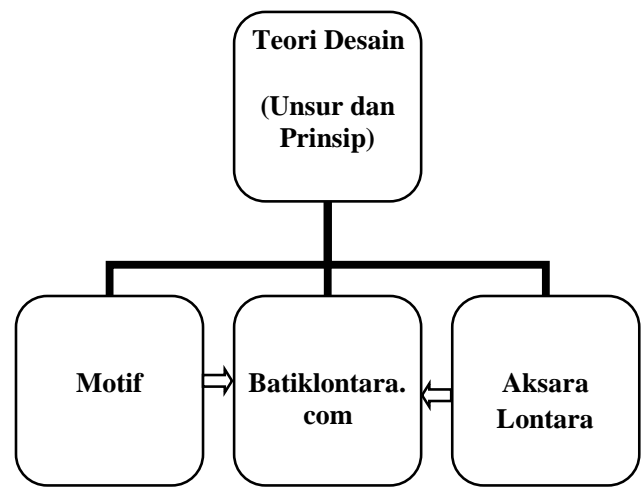

Gambar 1. Skema kerangka pikir

Kata desain berasal dari kata design (Bahasa Inggris) yang dapat berarti potongan, bentuk, model, pola, konstruksi, mode, atau tujuan. Kata design itu sendiri berasal dari kata designare (Bahasa Latin), namun ada pula yang berpendapat bahwa kata design merupakan kata yang berasal dari kata disegno yaitu istilah yang dikenal di Eropa yang berarti gambar atau rancangan yang dibuat oleh pematung atau pelukis sebelum mulai membuat patung atau lukisan. Dalam Bahasa Indonesia kata "desain" dapat juga diartikan rencana, yaitu rencana yang akan diterapkan untuk menghasilkan sesuatu, baik berupa barang maupun kegiatan tertentu.

a. Pengertian desain grafis

Desain grafis adalah suatu bentuk komunikasi visual yang menggunakan gambar untuk menyampaikan informasi atau pesan seefektif mungkin. Desain grafis diterapkan dalam desain komunikasi dan fine art. Seperti jenis desain lainnya, desain grafis dapat merujuk kepada proses pembuatan, metode merancang, produk yang dihasilkan ataupun disiplin ilmu yang digunakan (Casofa \& Isa, 2013:1).

b. Unsur desain

Unsur desain ialah unsur-unsur yang digunakan untuk mewujudkan desain. Unsur-unsur yang dimaksud adalah: (1) garis, (2) bidang, dan (3) warna.

c. Prinsip-prinsip desain

Hakekat suatu komposisi yang baik, jika suatu proses penyusunan unsur pendukung motif, senantiasa memperhatikan prinsip-prinsip komposisi (1) keseimbangan, (2) kontras, (3) irama, dan (4) kesatuan.

Dalam Kamus Besar Bahasa Indonesia (KBBI) (2008: 973), motif (motif) adalah corak. Motif adalah gambaran bentuk yang merupakan sifat dan corak suatu perwujudan (Untoro, 1979:21). Berbeda halnya dengan yang diungkapkan Susanto Sewan, yaitu motif merupakan kerangka gambar yang mewujudkan motif batik secara keseluruhan (Sewan, 1980: 212). Menciptakan gabar atau membuat motif adalah pekerjaan menyusun, merangkai, memadukan bentuk dasar motif, bentuk berbagai garis dan sedemikian rupa sehingga tercipta sebuah bentuk gambar motif baru yang indah, serasi, bernilai seni, serta orisinil (Suhersono, 2004: 14).

Aksara Lontara merupakan bahasa kebudayaan di Kerajaan Gowa yang digunakan dalam berbagai kegiatan perdagangan, pertanian, pemerintahan, penyebaran agama, dan kesusastraan. Bahasa Makassar dan Bahasa Bugis mempunyai lambang bunyi atau aksara tersendiri yang disebut aksara Lontara. Aksara Lontara mulai diperkenalkan pada masa pemerintahan Sombaya ri Gowa IX, Daeng Pamatte (1512-1546). Daeng Pamatte waktu itu menjabat sebagai syahbandar dan merangkap sebagai tomailalang, mangkubumi, Kerajaan Gowa. Ia dianggap oleh sebagian sejarawan sebagai pencipta huruf Lontara. Ia juga dikenal sebagai penulis pertama undang-undang pemerintahan kerajaan, silsilah Tomanurung, dan catatan harian 
kerajaan. Daerah Bugis mempunyai sistem abjad sendiri yang disebut aksara Lontara. Aksara ini memiliki 23 buah huruf dan 5 diakritik. Simbol aksara Lontara mewakili suku kata. Oleh karena itu, huruf Bugis adalah silabel. Penciptaan bentuk huruf Bugis dilatarbelakangi oleh suatu kepercayaan yang berpangkal pada pandangan mitologis, yang memandang alam semesta ini sebagai sulapa eppa walasuji (segi empat belah ketupat). Ke 23huruf Bugis silabel yaitu sebagai berikut:

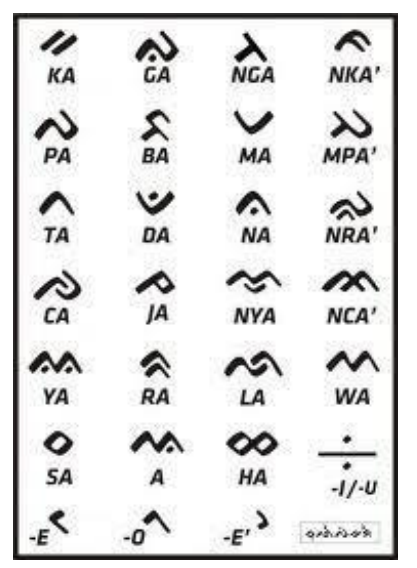

Gambar 2. Ina Sureq (Induk Huruf) Sumber:

https://www.google.com/url?q=https://ope nlibrarytelkomuniversity.ac.id/pustaka/file s/104327/jurnal_eproc/aplikasi-aksaralontara-makassar-berbasis-android.pdf

Jika ina sureq itu dibubuhi diakritik (tanda pembeda) tertentu dengan posisi tertentu pula, akan melambangkan atau mewakili suku kata tertentu pula. Diakritik ini dinamakan anaq sureq (anak huruf). Anaq sureq ini berjumlah lima buah, yaitu:

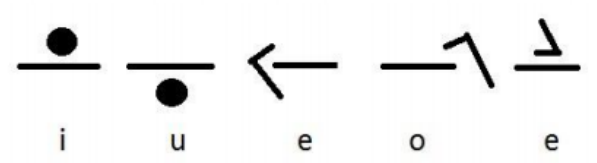

Gambar 3. Anaq Sureq (Anak Huruf) Sumber: Dokumen Universitas Telkom

(1) Simbol (i) posisinya di atas ina sureq, melambangkan bunyi /i/, (2) Simbol (u) posisinya di bawah ina sureq, melambangkan bunyi /u/, (3) Simbol (e) posisinya di depan ina sureq, melambangkan bunyi /e/ (taling), (4) Simbol (o) posisinya di belakang ina sureq, melambangkan bunyi /o/, (5) Simbol (e) posisinya di atas ina sureq, melambangkan bunyi /e/ (pepet) (Alex dkk, 2015: 1879).

Batiklontara.com adalah salah satu batik khas Sulsel yang berdiri sekitar 4 tahun yang lalu tepatnya pada tahun 2015 . Konsep dari Batiklontara.com ini sendiri berasal dari kearifan lokal dari tiap daerah di Sulsel. Dipilihnya motif Lontara sendiri bertujuan agar generasi berikutnya setidaknya memahami tentang aksara Lontara. Karena tidak dapat dipungkiri, penggunaan daun lontar untuk menulis aksara Lontara sudah jarang ditemui. Maka dari itu, diharapkan dengan adanya motif Lontara pada Batiklontara.com dapat merangsang visual generasi berikutnya agar tetap dapat melestarikan dan mempertahankan budaya aksara Lontara tersebut. Selain itu, sulapa eppa yang terdapat pada motif Lontara menyimbolkan tentang unsur sifat yang dimiliki oleh manusia, sehingga motif Lontara yang terdapat pada Batiklontara.com apat menyimbolkan unsur sifat dasar manusia.

Batiklontara.com terbagi menjadi 2 sistem pasar, yaitu corporate (yang berhubungan dengan badan hukum dan pemerintahan dan commercial (umum). Untuk pemilihan warnanya sendiri tergantung pasar dan konsumen. Untuk pasar commercial, warnanya mengacu pada warna-warna mencolok khas Sulawesi Selatan, seperti hijau, kuning, merah dan hitam. Sedangkan untuk pasar corporate tergantung permintaan instansi.

Batiklontara.com merupakan batik yang didesain di Makassar dan diproduksi oleh pengrajin batik yang ada di Pulau Jawa. Batik-batik ini memiliki motif dengan filosofi dan ciri khas tersendiri. Salah satu ciri khas Batiklontara.com yakni sedikitnya isen-isen atau aneka gambar yang berfungsi mengisi dan melengkapi motif pada batik (seperti titik dan garis) 
tambahan yang biasa ada pada batik. Batiklontara.com lebih mengangkat aksara Lontara untuk dijadikan motif batik. Hal tersebut dikarenakan keunikan, makna, serta nilai filosofis yang terkandung di dalamnya. Berikut beberapa contoh Batiklontara.com:

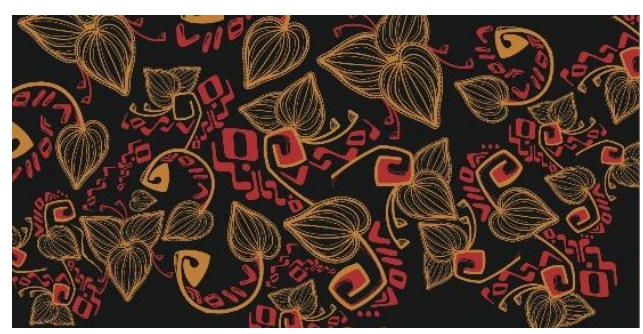

Gambar 4. Batik Lontara Leko Caddi (Dokumentasi: Mustakim, 2019)

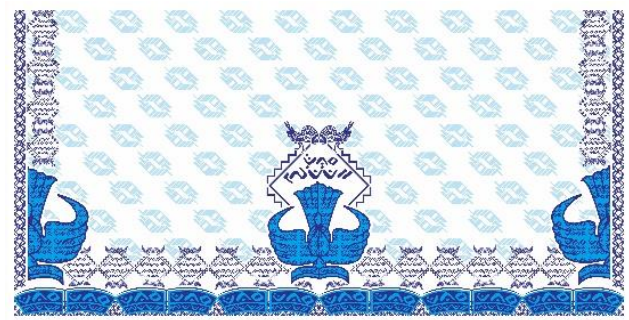

Gambar 5. Batik Dinas Pendidikan Kota Makassar (Dokumentasi: Mustakim, 2019)

\section{METODE PENELITIAN}

Berdasarkan masalah yang dikaji, penelitian ini merupakan penelitian deskriptif dengan metode survey. Metode deskriptif adalah metode yang digunakan untuk menggambarkan atau menganalisis suatu hasil penelitian tetapi tidak digunakan untuk membuat kesimpulan yang lebih luas (Sugiyono, 2012:29).

Sedangkan menurut Tika (1997:9) mengatakan bahwa survey adalah suatu metode penelitian yang bertujuan untuk mengumpulkan sejumlah besar data berupa variabel, unit atau individu dalam waktu yang bersamaan, data dikumpulkan melalui individu atau sampel fisik tertentu dengan tujuan agar dapat menggeneralisasikan terhadap apa yang diteliti. Variabel yang dikumpulkan dapat bersifat fisik maupun social.

Penelitian ini dilaksanakan di Café Lakopi, Jalan Hertasning. Sedangkan lokasi Batiklontara.com terletak di Jalan Adhyaksa 9 nomor 6, Kelurahan Pandang, Kecamatan Panakkukang, Kota Makassar. Pelaksanaanya direncanakan mulai bulan April 2018. Peneliti melakukan wawancara serta observasi yang dilaksanakan pada tanggal 10 Maret 2019.

Penelitian ini dilakukan untuk memperoleh data tentang motif Batiklontara.com, maka dipaparkan variabel penelitian yaitu: (a) Proses pembuatan desain motif Batiklontara.com, (b) Penerapan unsur dan prinsip desain dalam pembuatan desain motif Batiklontara.com.

Untuk memperjelas proses penelitian tentang pembuatan desain Batiklontara.com, maka diperlukan suatu prosedur penelitian sebagai acuan dalam pelaksanaan penelitian lapangan. Adapun prosedur penelitian tersebut adalah sebagai berikut:

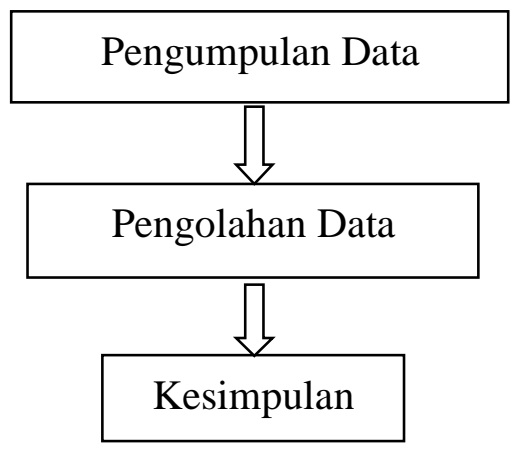

Gambar 6. Prosedur Penelitian

Untuk memperjelas sasaran penelitian dan tidak menimbulkan salah penafsiran terhadap variabel dalam penelitian ini maka perlu didefiniskan secara operasional, yaitu: (1) Proses pembuatan desain motif Batiklontara.com, mulai dari proses pembuatan sketsa awal sampai pengaplikasian desain jadi ke dalam bentuk mockup, (2) Penerapan unsur desain yang meliputi, garis, bidang, dan 
warna, dan penerapan prinsip desain yang meliputi keseimbangan, tekanan, irama, dan kesatuan dalam pembuatan desain motif Batiklontara.com.

Teknik pengumpulan data yang digunakan dalam proses penelitian ini mulai dari dokumentasi, observasi, serta wawancara. Hal ini dilakukan untuk mendukung hasil dari pengumpulan data tentang proses pembuatan desain motif batik beserta penerapan ilmu-ilmu desain dalam pembuatan desain motif batik tersebut sehingga tercipta motif batik pada Batiklontara.com. Sumber data berupa dokumentasi berupa foto-foto serta datadata melalui wawancara yang sangat berperan sebagai bahan penelitian.

Reduksi data, dengan menggolongkan serta memfokuskan pada pokok penelitian sehingga dilakukan pembuangan data-data yang tidak mendukung penyusunan laporan penelitian tersebut. Proses pemilihan data atas dasar tingkat relevansi dan kaitannya dengan setiap kelompok data, menyusun data dalam satuan-satuan sejenis, dan membuat susunan data sesuai dengan pokok penelitian. Sajian data, dengan menyajikan data yang diperoleh dari observasi, wawancara serta dokumentasi. Dalam penyajian data hasil penelitian disajikan secara verbal dan visual.

Penarikan kesimpulan dengan menyimpulkan data-data yang ada di dalam laporan penelitian tersebut secara ringkas dan jelas.

\section{HASIL PENELITIAN}

\subsection{Proses pembuatan desain motif Batiklontara.com}

\subsubsection{Menentukan tema dan ide}

Semua desain motif Batiklontara.com merupakan hasil gagasan sendiri dari pemilik dan desainer. Motif yang akan dibuat ditentukan temanya terlebih dahulu, misalnya batik untuk suku Bugis dan Makassar, sedangkan ide desainnya berangkat dari teks dan filosofi kemudian dikembangkan dan digambarkan dalam bentuk motif batik. Untuk ornamenornamen tambahan yang dipakai seperti logo, dan lain-lain hanya digunakan sesuai permintaan konsumen.

Adapun tema batik yang akan di desain adalah batik untuk masyarakat Sulawesi Selatan, khususnya suku Bugis dan Makassar. Motif yang dipilih untuk batik ini adalah motif daun sirih kecil (leko caddi). Leko caddi merupakan ritual seserahan dalam adat pernikahan suku Bugis dan Makassar yang bermakna mengerahkan segala yang terbaik untuk si mempelai. Jadi dengan hadirnya motif ini diharapkan dapat membuat si pemakai merasakan semua hal yang terbaik dalam hidup dan juga menghasilkan sesuatu yang terbaik dalam setiap hal yang dilakukan.

\subsubsection{Membuat Sketsa}

Setelah ide dan tema ditentukan, tahap selanjutnya dalam proses pembuatan desain adalah membuat sketsa. Proses pembuatan sketsa bisa dilakukan dengan menggunakan pensil dan spidol ataupun aplikasi Sketchbook.

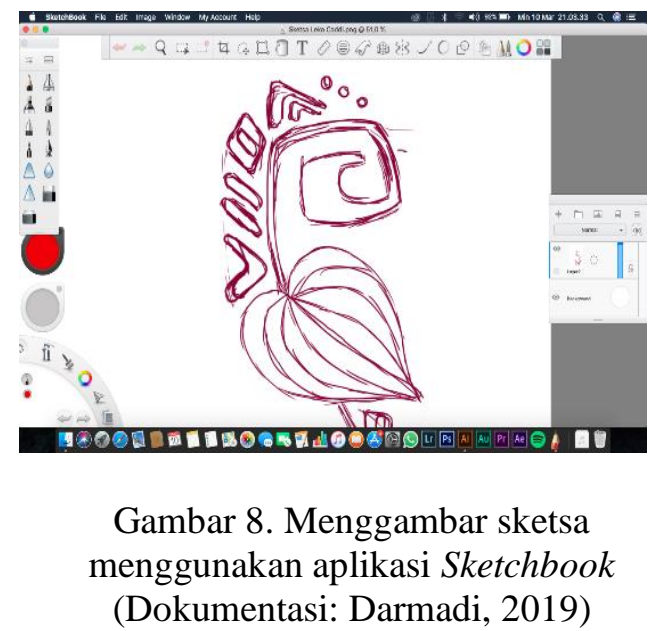

3.1.3. Sketsa awal diubah ke dalam bentuk gambar digital

Tahap selanjutnya yaitu sketsa awal yang telah selesai diubah ke dalam bentuk 
gambar digital. Sketsa motif dipindahkan ke aplikasi Adobe Illustrator CC.

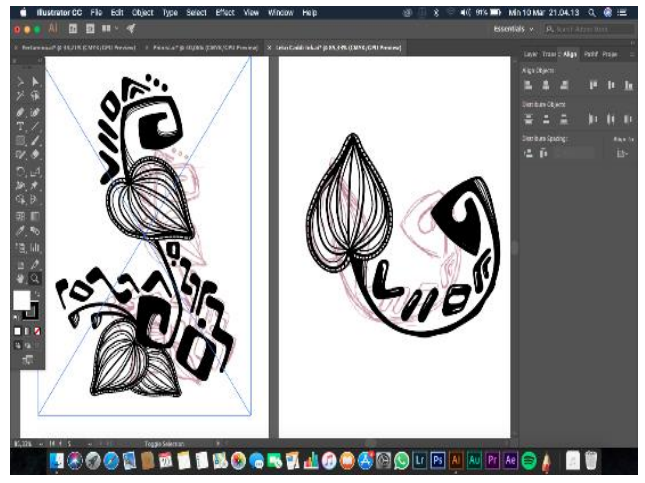

Gambar 9. Sketsa awal diubah ke dalam bentuk gambar digital

(Dokumentasi: Darmadi, 2019)

\subsubsection{Penyusunan komposisi pada ukuran kain batik}

Pada tahap ini, desain yang telah diubah ke dalam bentuk gambar digital kemudian diimpor satu persatu kemudian dikomposisikan ke dalam ukuran kain batik.

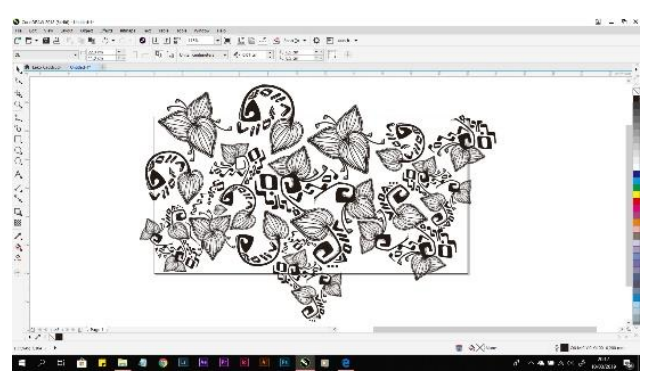

Gambar 10. Penyusunan komposisi motif pada ukuran kain batik

(Dokumentasi: Mustakim, 2019)

\subsubsection{Proses pewarnaan desain motif batik}

Pada tahap ini, desainer terlebih dahulu memberi warna pada motif aksara Lontara. Motif aksara Lontara kemudian diberi warna merah, dipadukan dengan warna kuning keemasan pada motif daun, dan warna hitam untuk background. Tool yang digunakan dalam proses pewarnaan adalah color palette, kemudian pilih warna-warna yang diinginkan dan aplikasikan.

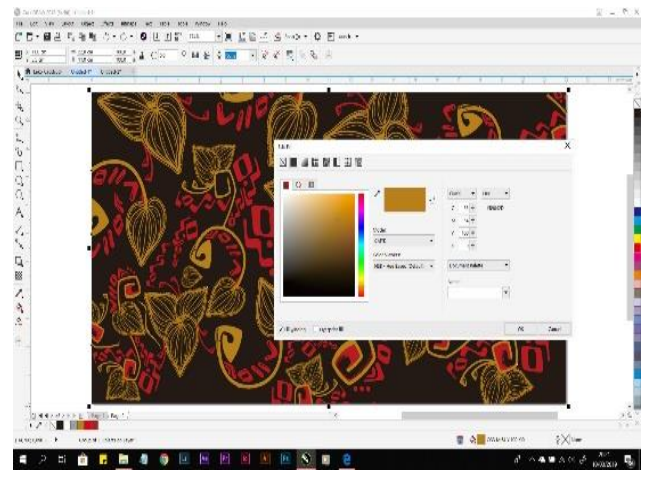

Gambar 11. Proses pewarnaan desain batik secara keseluruhan

(Dokumentasi: Mustakim, 2019)

3.1.6. Pengaplikasian desain motif batik jadi ke dalam bentuk mockup

Desain motif yang telah selesai kemudian dimasukkan ke aplikasi Adobe Photoshop CC untuk diaplikasikan ke dalam mockup dalam bentuk baju.

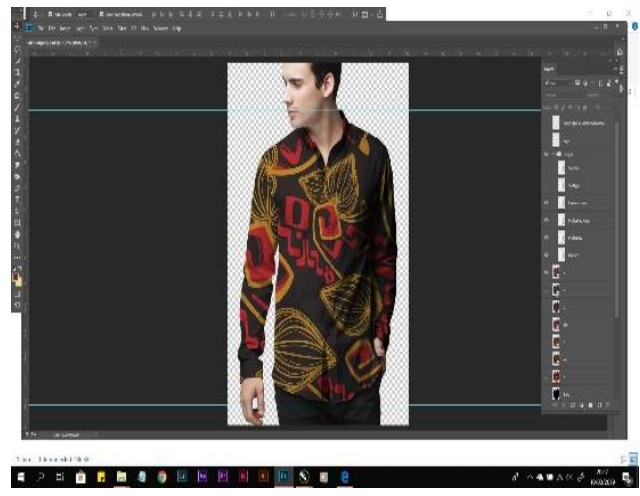

Gambar 12. Pembuatan mokup dalam bantuk baju

(Dokumentasi: Mustakim, 2019)

3.1.7. Hasil akhir dari proses pembuatan desain motif Batiklontara.com

Di bawah ini merupakan desain batik yang telah diaplikasikan ke dalam bentuk mockup yang merupakan tahap akhir dari proses pembuatan desain Batiklontara.com. 


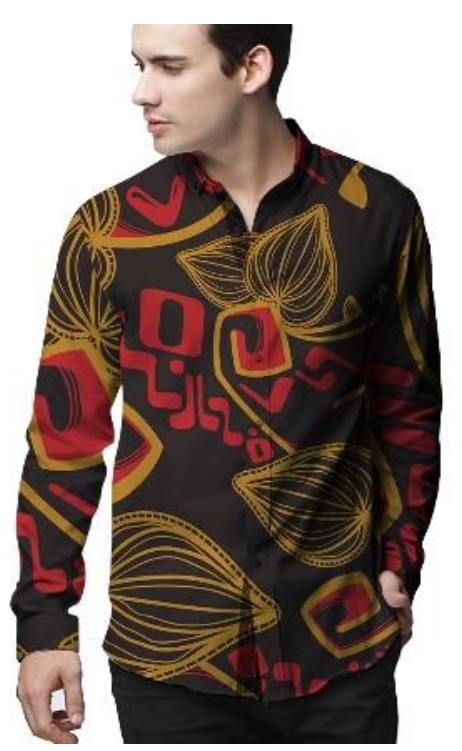

Gambar 13. Hasil dari pengaplikasian kain batik ke dalam bentuk mockup

(Dokumentasi: Mustakim, 2019)

3.2. Penerapan Unsur dan Prinsip pada Desain Motif Batiklontara.com

3.2.1. Penerapan unsur desain pada pembuatan desain motif Batiklontara.com

1. Garis

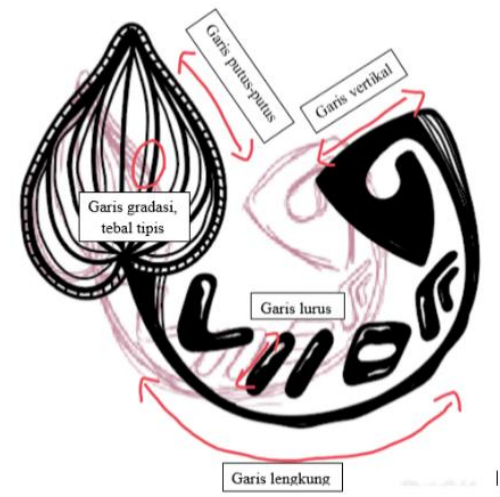

Gambar 14. Wujud garis pada desain motif batik (Dokumentasi: Maghfira Maulani Patappa, 2019)

Pada desain motif Btiklontara.com, terdapat beberapa wujud garis yang bervariasi. Misalnya garis lengkung, garis lurus, garis putus-putus, garis vertikal, garis diagonal, dan garis gradasi tebal tipis.
2. Bidang

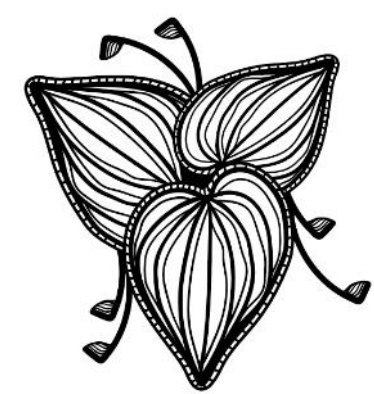

Gambar 15. Contoh bidang pada motif batik (Dokumentasi: Darmadi, 2019)

Pada Batiklontara.com, dapat kita lihat bahwa desain batik tersebut menggunakan campuran bidang geometris dan non geometris.

3. Warna

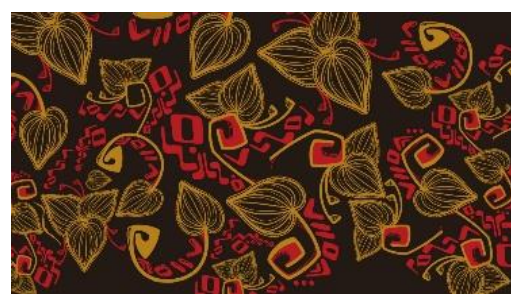

Gambar 16. Kesan warna dalam desain batik(Dokumentasi: Mustakim, 2019)

Pada Batiklontara.com, pemilihan warna biasanya berdasar kepada arti dan makna dari batik itu sendiri, misalnya warna merah yang memiliki kesan berani dan kuat, warna kuning keemasan memiliki kesan mewah dan elegan, dan warna hitam yang memiliki kesan misterius.

\subsubsection{Penerapan prinsip desain pada pembuatan desain motif Batiklontara.com}

\section{Keseimbangan}

Keseimbangan berarti pembagian sama berat dalam komposisi desain. Batiklontara.com menggunakan prinsip keseimbangan asimetris, yaitu penyusunan elemen-elemen desain yang tidak sama 
antara sisi kiri dan kanan namun terasa seimbang.

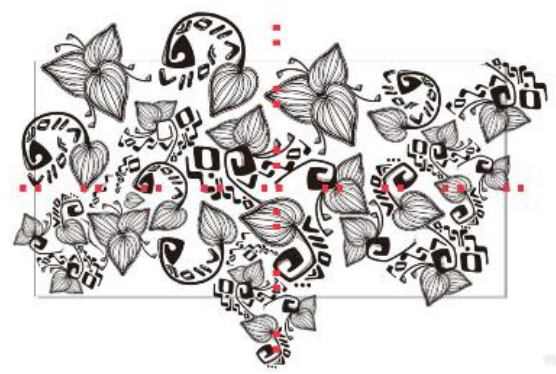

Gambar 17. Contoh prinsip keseimbangan asimetris pada batik (Dokumentasi: Maghfira Maulani Patappa, 2019)

\section{Penekanan}

Prinsip penekanan yang ingin disampaikan kepada audiens adaah kontras. Penerapan kontras pada motif aksara lontara dan motif daun sirih membuatnya terlihat berbeda dan menjadi pusat perhatian dengan background berwarna hitam.

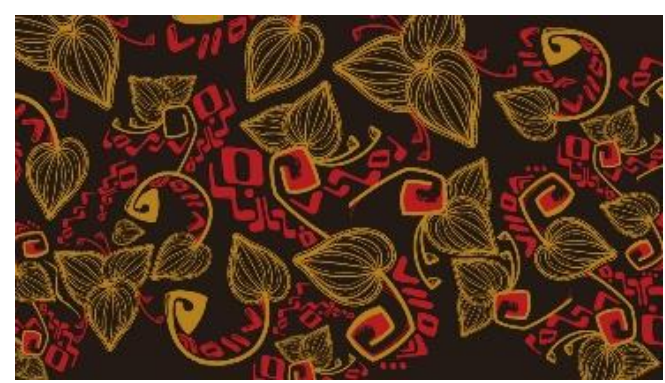

Gambar 18. Penggunaan kontras terang pada motif daun sirih dan aksara lontara(Dokumentasi: Mustakim, 2019)

\section{Irama}

Prinsip irama pada desain motif Batiklontara.com di bawah ini menghadirkan perulangan visual tapi tidak sama persis. Repetisi ini disertai perubahn bentuk, ukuran, ataupun posisi.

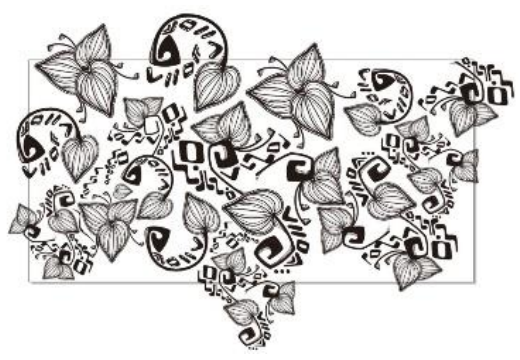

Gambar 19. Repetisi motif yang tidak sama persis (Dokumentasi: Mustakim, 2019)

4. Kesatuan

Pada Batiklontara.com, perpaduan antara ilustrasi motif, warna, dan tipografinya terlihat harmonis dan menarik untuk dipandang.

\section{SIMPULAN DAN SARAN \\ 4.1. Kesimpulan}

1. Proses pembuatan desain motif Batiklintara.com, yaitu menggambar sketsa menggunakan aplikasi Sketchbook atau bisa juga dengan menggunakan pensil ataupun spidol. Sketsa wal diubah menjadi gambar digital menggunakan aplikasi Adobe Illustrator $C C$, penyusunan komposisi dan proses pewarnaan menggunakan aplikasi Adobe Photoshop CC.

2. Proses pembuatan desain motif Batiklontara.com tetap memperhatikan unsur-unsur desain yaitu garis, bidang, dan warna, dan juga berpegang pada prinsip-prinsip desain, yaitu keseimbangan, tekanan, irama dan kesatuan.

\subsection{Saran}

1. Disarankan agar di lokasi penelitian ditampilkan display kain batik agar mempermudah peneliti dan pengunjung yang ingin mengamati dan melihat kain batik tersebut secara langsung.

2. Model penulisan aksara lontara pada desain batik agar diperhatikan dengan seksama terlebih dahulu ketika 
diaplikasikan ke dalam bentuk mockup untuk menghindari salah penulisan yang menyebabkan konsumen kebingungan untuk mengartikan aksara lontara tersebut.

3. Beberapa sumber ide seperti kebudayaan, legenda-legenda, dan adat istiadat yang ada di Sulawesi Selatan dapat dijadikan ide dalam pembuatan desain motif Batiklontara.com guna meningkatkan nilai jual dan menambah kekayaan motif batik di Sulawesi Selatan.

\section{DAFTAR PUSTAKA}

Alex Verawati Herman, Asniar, Aji Pramuko. 2015. E-Proceeding of Applied Science: Vol.1, No. 3. Aplikasi Aksara Lontara Makassar Berbasis

Android.(Online)https://www.goog le.com/url?q=https://openlibrarytel komuniversity.ac.id/pustaka/files/1 04327/jurnal_eproc/aplikasiaksara-lontara-makassar-berbasisandroid.pdf. Bandung: Universitas Telkom (diakses tanggal 29 Desember 2017).

Anggiasari, Yunita. 2015. "Batik Gringsing

Kebumen".Skripsi/Tidak diterbitkan.(Online) https://eprints.uny.ac.id/23305/

Yogyakarta: Universitas Negeri Yogyakarta (diakses tanggal 29 Desember 2017).

Bimantara, Rizqi Ilzha. 2017. Aksara Lontara. (Online), https://id.wikipedia.org/wiki/Aksar a_Lontara(diakses tanggal 29 Desember 2017).

Bogdam, Robert dan Taylor. 1992. Pengantar Metode Penelitian Kualitatif. Terjemahan oleh Arief Ruchan. Surabaya: Usaha Nasional.
Casofa Fachmy, Isa Alib. 2013. Gerbang Kreativitas: Jagat Desain Grafis. Jakarta: Bumi Aksara.

Darsono. 2004. Seni Rupa Modern. Bandung: Rekayasa Sains.

Dofa, Anesia Aryunda. 1996. Batik Indonesia. Jakarta: Golden Terayon Press.

Gurbanatara, Arian. 2016. Keberagaman Indonesia (Online) https://www.kompasiana.com/aria n.gurbantara/keragaman-indonesia (diakses tanggal 5 November 2017).

H.B. Sutopo. 2002. Metodologi Penelitian Kualitatif Dasar Teori dan Terapannya. Surakarta: UNS Press.

Iskandar. 2008. Metodologi Penelitian Pendidikan dan Sosial (Kuantitatif dan Kualitatif). Jakarta: GP Press.

Kamus Besar Bahasa Indonesia (KBBI). 2008. Luar Jaringan (offline). Jakarta. Pusat Bahasa Departemen Pendidikan Nasional

Kirk J, Miller M.L. 1986. Reliability and Validity in Qualitative Research. Beverly Hills, CA: Sage Publications.

Moleong, Lexy J. 2008. Metodologi Penelitian Kualitatif. Bandung: PT Remaja Rosdakarya.

Nursantara, Yayat. 2004. Kesenian Seni Rupa, Musik, Tari, dan Drama. Jakarta: Erlangga.

Pabundu Tika, Moh. 1997. Metode Penelitian Geografi. Jakarta: PT Gramedia Pustaka Utama.

Prawira, Sulasmi Darma. 1989. Warna sebagai Salah Satu Unsur Seni dan Desain. Jakarta: Departemen Pendidikan dan Kebudayaan, Direktorat Jenderal Pendidikan Tinggi, Proyek Pengembangan Lembaga Tenaga Kependidikan.

Purnomo, Heri. 2004. Nirmana, Dwimatra. Diktat. Yogyakarta: Jurusan Pendidikan Seni Rupa dan Keterampilan Kerajinan, Fakultas Bahasa dan Seni, UNY. 


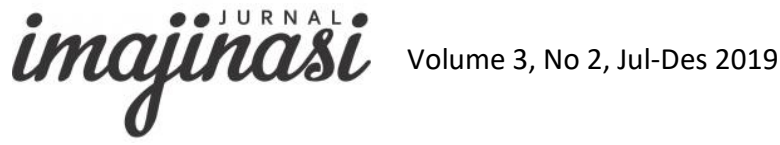

Sa'du, Abdul Aziz. 2013. Buku Praktis: Mengenal dan Membuat Batik. Yogyakarta: Pustaka Santri.

Sachari Agus, Sunarya Yan Yan. 1998. Modernisme: Tinjauan Historis Desain Modern. Bandung: Departemen Pendidikan dan Kebudayaan.

Said, Abdul Azis. 2006. Dasar Desain Dwimatra. Makassar: Badan Penerbit UNM.

Sewan, Susanto. 1973. Seni Kerajinan Batik Indonesia. Jakarta: Balai Penelitian Batik dan Kerajinan, Lembaga Penelitian dan Pendidikan Industri, Departemen Perindustrian.

Sipahelut Atisah, Petrussumadi. 1991. Dasar-Dasar Desain. Jakarta: Departemen Pendidikan dan Kebudayaan.

Sugiyono. 2012. Memahami Penelitian Kualitatif. Bandung: ALFABETA

Suhersono, Heri. 2004. Desain Bordir Motif Flora dan Dekoratif. Jakarta: PT Gramedia Pustaka Utama.

Untoro, Bambang. 1979. Pola-pola Batik dan Pewarnaan. Jakarta: Departemen Pendidikan dan Kebudayaan.

Utami, Anadia Natasyah. 2016. "Batik Makassar".Skripsi/Tidak diterbitkan. Surakarta: Universitas Sebelas Maret.

Wulandari, Ari. 2011. Batik Nusantara, Makna Simbolik (Cara Pembuatan, dan Industri Batik). Yogyakarta: CV. Andi Offset. 